\author{
Revista Brasileira de Educação do Campo \\ The Brazilian Scientific Journal of Rural Education \\ ARTIGO/ARTICLE/ARTÍCULO \\ DOI: http://dx.doi.org/10.20873/uft.rbec.e7323
}

\title{
Pedagogia da Alternância e Educação do Campo: dos hibridismos epistemológicos à simetria com a Educação Popular
}

\begin{abstract}
Úrsula Adelaide de Lélis ${ }^{1}$, Magda Martins Macedo ${ }^{2}$, Leandro Luciano da Silva ${ }^{3}$, Maria Auxiliadora Amaral Silveira Gomes ${ }^{4}$ 1, 2, 3, 4 Universidade Estadual de Montes Claros - UNIMONTES. Departamento de Métodos e Técnicas Educacionais e Departamento de Educação - Centro de Ciências Humanas (CCH). Departamento de Direito Público Substantivo - Centro de Ciências Sociais Aplicadas (CCSA). Campus Universitário Professor Darcy Ribeiro. Avenida Rui Braga, s/n, Vila Mauricéia, Montes Claros - MG. Brasil.

Autor para correspondência/Author for correspondence: ursulalelis@gmail.com
\end{abstract}

RESUMO. A Pedagogia da Alternância vem se constituindo como possibilidade metodológica para a educação dos povos do campo, dada sua convergência pedagógica e política com os princípios da Educação do Campo. Contudo, experiências híbridas têm revelado que os fundamentos epistemológicos que sustentam essa Pedagogia têm sido colocados à margem das práticas, esvaziando as potencialidades emancipadoras da Alternância. Partindo dessas acepções, este texto, resultado de reflexões teóricas, discute os princípios epistemológicos que fundamentam a Pedagogia da Alternância, compreendida enquanto práxis forjada na unidade tempo e espaço, e suas contribuições para a formação emancipatória dos povos do campo. A assunção do papel político da epistemologia da Alternância promove o rompimento da formação calcada na dicotomia tempo-escola e tempo-comunidade. Rompe com uma práxis fetichizada promovendo a transformação-emancipação dos sujeitos e suas comunidades. As simetrias entre Educação do Campo e Pedagogia da Alternância evocam, necessariamente, ultrapassar as variantes híbridas que essa Pedagogia vem assumindo no âmbito da formação dos povos do campo. Exige conceber a unidade que produz o tempo-escola e o tempo-comunidade como processo político formativo.

Palavras-chave: Pedagogia da Alternância, Educação do Campo, Unidade Tempo-Escola e Tempo-Comunidade, Emancipação.

\begin{tabular}{|l|l|l|l|l|l|l|} 
RBEC & Tocantinópolis/Brasil & v. 4 & e7323 & $10.20873 /$ uft.rbec.e7323 & 2019 & ISSN: 2525-4863 \\
\hline
\end{tabular}




\title{
Pedagogy of Alternation and Rural Education: from epistemological hybridism's to symmetry with Popular Education
}

\begin{abstract}
Pedagogy of alternation has been considered a methodological possibility for the rural people's education, given its pedagogical and political convergence with the principles of Rural Education. However, hybrid experiences have revealed that the epistemological foundations that underpin this Pedagogy have been placed on the margin of practices, emptying the emancipatory potentialities of Alternation. Starting from these meanings, this text which is the result of theoretical reflections, discusses the epistemological principles that underlie the Pedagogy of Alternation, understood as a praxis forged in the unit of time and space, and its contributions to the emancipatory formation of rural people. The assumption of the political role of the Alternation epistemology promotes the disruption of formation based on the time-school and timecommunity dichotomy. It breaks with a fetishized praxis promoting the transformation-emancipation of these people and their communities. The symmetries between Rural Education and Alternation Pedagogy necessarily evoke overcoming the hybrid variants that this Pedagogy has been assuming in the context of rural people's education. It requires conceiving the unity that produces time-school and time-community as a formative political process.
\end{abstract}

Keywords: Pedagogy of Alternation, Rural Education, Timeschool and Time-Community Unit, Emancipation. 


\section{Pedagogía de la Alternancia y Educación del Campo: de los hibridismos epistemológicos a la simetría con la Educación Popular}

RESUMEN. La Pedagogía de La Alternancia se está constituyendo como una posibilidad metodológica para la educación de los pueblos del campo, dada a su convergencia pedagógica y política con los principios de la Educación del Campo. Sin embargo, experiencias híbridas han revelado que los fundamentos epistemológicos que sustentan esta Pedagogía han sido colocados al margen de las prácticas, vaciando las potencialidades emancipadoras de la Alternancia. Partiendo de estas acepciones, este texto, resultado de reflexiones teóricas, discute los principios epistemológicos que fundamentan la Pedagogía de la Alternancia, comprendida como praxis forjada en la unidad de tiempo y espacio, y sus contribuciones para la formación emancipadora de los pueblos del campo. La asunción del papel político de la epistemología de la Alternancia, promueve el rompimiento de la formación calcada en la dicotomía Tiempo - escuela y tiempo-comunidad. Rompe con la praxis fetichizada promoviendo la transformación-emancipación de los sujetos y sus comunidades. Las simetrías entre Educación del Campo y la Pedagogía de la Alternancia evocan, necesariamente, exceden las variantes híbridas que esta Pedagogía viene asumiendo en el ámbito de la formación de los pueblos del campo. Exige concebir la unidad que produce el tiempo-escuela y el tiempo comunidad como proceso político formativo.

Palabras clave: Pedagogía de la Alternancia, Educación del Campo, Unidad Tiempo-Escuela y Tiempo-Comunidad, Emancipación. 


\section{Introdução}

Os 21 anos de luta "Por uma Educação do Campo", no Brasil, reafirmam a contradição como força genuína de todo movimento. Os debates e embates travados em seu bojo renovam cotidianamente sua agenda, não pela superação de demandas, mas pelas implicações produzidas no âmbito das contradições que permeiam os modelos de educação particularistas e públicos no país.

Nessa seara, os desafios que se interpõem à Educação do Campo vão desde a garantia de recursos financeiros para implementação de projetos e programas à necessidade de revisões conceituais das relações escola-culturarealidade e à transformação didáticometodológica das práticas docentes ao repensar o papel da escola, dentre outros.

Eleger a mais urgente das demandas é uma tarefa, por certo, complexa, dado que a histórica negligência do Estado brasileiro com os povos do campo remonta a mais de 500 anos e ainda assenta-se em questões básicas como assinalado acima. Pesquisa da Confederação da Agricultura e Pecuária do Brasil (CNA) (Guia do Estudante, 2010), em 50 escolas do campo de dez estados brasileiros, mostrou que, em 2010, 70\% delas não tinham biblioteca, $66 \%$ não contavam com computador e o quadro negro era a única ferramenta pedagógica encontrada e, em mais de $70 \%$ dessas escolas, o mimeógrafo ainda era utilizado para reproduzir as atividades. Apoiados na pesquisa que produziu o "Dados do Censo Escolar de 2014", Reis e Moreno (2015) revelaram que somente 5\% das escolas do campo contavam com rede de esgoto e $80 \%$ dependiam de fossas; $27 \%$ das rurais tinham rede de água, as demais se valiam de poços artesianos, cacimbas ou fontes naturais; e em $14 \%$ o serviço de água era inexistente.

Cruz e Monteiro (2019) sublinham que as populações campesinas ainda são as mais afetadas pela baixa qualidade da escolarização e concentram os maiores percentuais de analfabetismo funcional, apontando os desafios postos ao cumprimento das metas do atual Plano Nacional de Educação (PNE) (Brasil, 2018) de elevar as taxas de alfabetização de crianças e da população com 15 anos, chegando a erradicar o analfabetismo absoluto e reduzir em $50 \%$ a taxa de analfabetismo funcional até 2024. Em 2018, eram 5,5 milhões de matrículas no campo, atingindo 99\% de crianças de 6 a 14 anos e 87,4\% de jovens de 15 a 17 anos (Cruz \& Monteiro, 2019), o que, contudo, não equivale a índices de aprendizagem, confirmando a necessidade de políticas públicas com proposições de ações 
afirmativas para dirimir as discrepâncias sociais vivenciadas pelas comunidades campesinas.

Desse elenco de ausências e negligências com a Educação do Campo, no que toca às questões políticopedagógicas, uma das mais desafiadoras e urgentes refere-se à oferta de educação contextualizada às diversas populações do campo enquanto estratégia políticopedagógica para a construção de aprendizagens baseadas nos princípios da Educação Popular. Uma educação campesina contextualizada em sua cosmovisão, em seu modo de vida, em seu ritmo, em suas crenças e em seu trabalho, cuja raiz é a forte relação com o ambiente natural: a terra, as águas, as árvores e os animais, o modus vivendi, requer uma educação que se integre e não se afaste da cultura secularmente gestada e preservada pelas populações do campo.

No âmbito normativo, a Constituição Federal (Brasil, 1988), quando no seu art. 205 afirma a educação como dever do Estado e da família, promovida e incentivada com a colaboração da sociedade para o desenvolvimento da pessoa, seu preparo para o exercício da cidadania e sua qualificação para o trabalho, sublinha a necessidade de percepção diferenciada entre modo de vida e de trabalho urbano e modo de vida e de trabalho rural.

Em 1996, a Lei Diretrizes e Bases da Educação Nacional (LDB) (Brasil, 1996), dando continuidade e operacionalidade ao que determina a Constituição Federal, insistiu na garantia do direito à educação e em sua especificidade de atendimento para os povos do campo, conforme se verifica na redação do seu art. 28:

... na oferta de educação básica para a população rural, os sistemas de ensino promoverão as adaptações necessárias à sua adequação às peculiaridades da vida rural e de cada região, especialmente: I conteúdos curriculares e metodologias apropriadas às reais necessidades e interesses dos alunos da zona rural; II - organização escolar própria, incluindo adequação do calendário escolar às fases do ciclo agrícola e às condições climáticas; III - adequação à natureza do trabalho na zona rural (grifos nossos).

Ainda em consonância com a Constituição Federal, o art. 23 da LDB (Brasil, 1996) indica que a Educação Básica poderá

... organizar-se em séries anuais, períodos semestrais, ciclos, alternância regular de estudos, grupos não seriados, com base na idade, na competência e em outros critérios, ou por forma diversa de organização, sempre que o interesse do processo de aprendizagem assim o recomendar (grifos nossos). 
Esses preceitos estão delineados no âmbito de outras normativas do Ministério da Educação (MEC), em especial nas Diretrizes Operacionais para a Educação Básica nas Escolas do Campo de 2002 (Brasil, 2002), e na Resolução $n^{\circ}$ 2/2008 (Brasil, 2008), da Câmara de Educação Básica do MEC, que estabelece as diretrizes complementares para o desenvolvimento de políticas públicas de atendimento à Educação Básica do Campo.

A Pedagogia da Alternância tem se revelado como possibilidade para atender ao desafio da educação contextualizada do campo: a unicidade tempo-escola e tempocomunidade proporciona aos alunos envolverem-se em suas reflexões nesses espaços e tempos em interação completa com sua realidade, sua família e comunidade de onde extraem elementos, desafios e questões de sua cotidianidade que, problematizadas, circunscreverão estudos para apresentação de possibilidades que possam, se não solucionar os problemas vividos, encaminhar proposições e reflexões necessárias a sua viabilização. Pela educação contextualizada nesse cenário político, pedagógico, social e cultural, ocasionado pelos princípios da Alternância, se constituiria também a emancipação dos sujeitos que (con)vivem (n)essa experiência.
Em 2006, o Parecer CNE/CEB n ${ }^{\circ} 1$ (Brasil, 2006) dispôs sobre os dias letivos para a aplicação da Pedagogia de Alternância nos Centros Familiares de Formação por Alternância (CEFFA), apontando como a instância governamental concebe essa Pedagogia. Atualmente, no Brasil, são dezenas de experiências que têm como proposta conceitual e pedagógica a Alternância: a Escola Geraizeira/Assentamento Tapera-MG, Escolas Famílias Agrícolas (EFA), Casas Familiares Rurais (CFR), Escolas Rurais contextualizadas acompanhadas por instituições como o Serviço de Tecnologia Alternativa (SERTA/PE), o Instituto Regional da Pequena Agropecuária Apropriada (IRPAA/BA), o Movimento de Organização Comunitária (MOC/BA), a Universidade Estadual de Feira de Santana (UEFS/BA), dentre outras.

Entretanto, experiências de Alternância (Queiroz, 2004; Souza, 2008; Silva, 2017; Zancanella \& Detogni, 2019) têm revelado matizes híbridos para essa Pedagogia, os quais levantam questionamentos sobre a clareza e a realização conforme seus fundamentos epistemológicos na constituição das práticas escolarizadas; isso incide diretamente na formação dos povos do campo e na realização de "Uma Educação Do Campo", enquanto “... categoria de 
análise da situação ou de práticas e políticas de educação dos trabalhadores do campo ...”. (Caldart, 2012, p. 257).

Os marcos legais e a literatura mostram avanços na compreensão das singularidades e demandas próprias dos povos do campo, fornecendo subsídios sociais, culturais, políticos e pedagógicos para a construção de uma educação que nasça do campo e não para o campo, demarcando a relevância do contexto onde seus sujeitos trabalham e produzem a vida. Contudo, é preciso salientar que qualquer perspectiva de educação contextualizada, que tenha como referência a Alternância, não se realiza se não estiver idiossincraticamente entrelaçada aos princípios epistemológicos que circunscrevem essa Pedagogia. Perspectivas associativas, complementares, integrativas ou sobrepostas, que compreendem a Alternância pela junção escola e comunidade em tempos variados, afastam-se desses princípios pela negação da sua essência que, para além do fenômeno, requer uma compreensão baseada na unidade que constitui tempos e espaços.

Este é, portanto, o objetivo deste texto: discutir os princípios epistemológicos que fundamentam a Pedagogia da Alternância, compreendida enquanto práxis forjada na unidade tempo e espaço, e suas contribuições para a formação emancipatória dos povos do campo. Parte-se de apontamentos sobre as composições e aproximações que convergem a Pedagogia da Alternância e a Educação do Campo para, em seguida, analisar os princípios epistemológicos da Alternância em simetria com a Educação Popular e porfiar a unidade dos contrários como eixo fundante do papel político da epistemologia na Pedagogia da Alternância.

\section{Educação do Campo e Pedagogia da Alternância: composições aproximações}

Os modelos estatais de educação destinados aos povos do campo se pautaram, historicamente, por objetivos ligados a aspectos econômicos e políticos. Da fixação do homem rural à terra, para garantia de mão de obra servil e barata, passando pelos movimentos em massa pela alfabetização de camponeses, projetos e programas ladearam-se pela descontextualização político-pedagógica, pelo atendimento aos interesses dos sistemas político e econômico via políticas verticalizadas, e na perspectiva de materialização da submissão do agrário brasileiro ao projeto hegemônico do modo de produção capitalista (Calazans, Castro \& Silva, 1981) 
Nesse sentido, segundo Silva e Martins (2015), a lógica desenvolvimentista sempre esteve presente em tais modelos, assim como os insumos e a crescente mecanização. Destarte, o processo brasileiro de industrialização ditou as propostas educacionais e atribuiu à educação o papel de responder pelas demandas do desenvolvimento. $\mathrm{O}$ propósito da educação rural, especialmente entre os anos 1920 e 1970, se identificava com os objetivos da modernização importada, com foco em integrar as populações rurais ao progresso que poderia advir do desenvolvimento capitalista, sem se preocupar com os sujeitos, ou seja, com os destinatários da educação rural (Silva \& Martins, 2015).

Nesse meandro, o Movimento de Educação de Base (MEB) - organismo da sociedade civil, vinculado à Conferência Nacional dos Bispos do Brasil (CNBB) -, a partir dos anos 1960, inseriu outra forma de fazer educação na área rural, fundamentando-se nos princípios da Educação Popular. Ainda hoje, o MEB (2019, s. p.) atua em

... áreas populacionais do País em que os indicadores socioeconômicos revelam situação de pobreza e, consequentemente, índices sociais e econômicos abaixo dos desejados. As ações de mobilização social, de alfabetização de jovens e adultos e de educação de base são responsabilidade de equipes regionais em cada uma das unidades da federação em que atuamos ... [e visam] contribuir para promoção humana integral e superação da desigualdade social por meio de programas de educação popular libertadora ao longo da vida.

Contudo, foi a perspectiva de educação rural vinculada aos propósitos desenvolvimentistas que direcionou a multiplicidade de programas pontuais e episódicos desenvolvidos pelos órgãos governamentais, nas épocas seguintes, pautados pela política pública verticalizada e descontextualizada.

Por outro lado, outros movimentos sociais esforçaram-se por instaurar projetos consonantes com a realidade rural, mas que também se caracterizavam pela pontualidade e especificidades, sem força e subsídios para alcançar a totalidade rural brasileira. Contornos mais definidos e de abrangência nacional se delinearam somente a partir da década de 1980, a partir da interferência de movimentos sociais do campo na disputa pela educação, em especial do Movimento dos Trabalhadores Rurais Sem Terra (MST).

A maior mobilização e de alcance nacional se deu em 1997, com a realização do I Encontro Nacional de Educadores e Educadoras da Reforma Agrária (ENERA), quando se cunhou o termo Educação do Campo enquanto proposta de reflexões e luta por uma educação 
horizontal, contextualizada às necessidades e interesses do povo campesino e da reforma agrária, partindo do fundamento de que educação compreende os mais diversos processos sociais de formação de sujeitos de direitos. Essa Educação

... identifica também uma reflexão pedagógica que nasce das diversas práticas de educação desenvolvidas no campo e/ou pelos sujeitos do campo. É uma reflexão que reconhece o campo como um lugar onde não apenas se reproduz, mas também se produz pedagogia; reflexão que desenha traços do que pode se constituir um projeto de educação ou formação dos sujeitos. (Caldart, 2011, p. 154).

Por conseguinte, reconhece-se o campo não mais como sinônimo de atraso, ou rural, mas como locus da vida, voltando-se os olhares para os sujeitos que lá produzem suas vidas, que constroem suas trajetórias por meio das diversidades ambientais, econômicas e sociais, condições próprias do caráter contraditório do capital. A Educação do Campo passa a evidenciar em si o conflito de classes e um espaço de disputas por direitos e pela implementação de políticas públicas que os materializem por meio de medidas, projetos e programas que atendam aos sujeitos do campo em suas especificidades políticas, sociais e culturais. Assim, a educação adjetivada com "campo" assume conotações que transcendem práticas pedagógicas e como instrumento de transformação do campo brasileiro “... inaugura $\mathrm{o}$ reconhecimento do campo como lócus de transformação e reprodução da vida, simboliza a luta de classe e a resistência daqueles que vivem o campo". (Silva \& Martins, 2015, p. 95).

A Educação do Campo é, fundamentalmente, uma proposta de projeto contra hegemônico, que se opõe à perspectiva ruralista pedagógica e supera o estigma do atraso e da pauperização, municiando a população do campo para a continuidade da luta contra a reprodução social que, num sistema capitalista, é sempre desigual e atinge a todos.

Não obstante o debate sobre a Educação do Campo ter ganhado corpo há mais de 20 anos, ela ainda é um tema em disputa e em constante ressignificação, reflexionando qualquer tentativa de cristalização conceitual, dado que sua manifestação no campo vai depender dos sujeitos que a operacionalizam. Portanto, não se trata de uma educação estática, pronta e acabada, mas uma proposta que envolve práticas educativas variadas e em constante movimento, assim como indica a denominação "Movimento por Uma Educação do Campo".

$\mathrm{Na}$ perspectiva deste texto, uma proposta metodológica que abarca os fundamentos políticos e pedagógicos da 
Educação do Campo é a Pedagogia da Alternância, que se apresenta como

... potencializadora de transformações sociais no campo, porque a Alternância envolve tempos e espaços contínuos que não estão dissociados ou despojados de suas peculiaridades: pessoas, políticas locais, ambientes, escassez, unidade produtiva, família e comunidade, parte das realidades sociais e produtivas dos sujeitos diretamente envolvidos no processo educativo, ou seja, trata-se de uma proposta de educação contextualizada. (Silva, 2017, p. 81).

A possibilidade dessa formação avançar para além dos muros da escola, e com finalidade emancipatória, aproxima a Pedagogia da Alternância à Educação do Campo, em consonância com os preceitos da Educação Popular.

A Pedagogia da Alternância, que tem sua origem na Maison Familiale Rurale (MFR), na França, em 1935, influenciou a criação das Escolas Famílias Agrícolas no Brasil. Constituindo-se como um dos fundamentos norteadores das MFR, originalmente, ela pressupõe “... a alternância de etapas de formação entre a Maison Familiale e a propriedade familiar como princípio norteador da prática pedagógica ...”. (Souza, 2008, p. 2). Sob esse princípio, constituem-se períodos de estudos na escola e nas comunidades no decorrer dos cursos, valorizando a cultura e a formação dos sujeitos do campo e possibilitando-lhes continuarem a residir nas suas comunidades de origem.

Não sem embargo para as escolas do campo, outra reflexão importante implícita na concepção de Alternância é a percepção de que a relação tempo-espaço das populações rurais é diferenciada das populações que vivem nas cidades e sedes dos pequenos municípios. Seu modo de produção é familiar e comunitário; são pais, mães, filhos, parentes próximos, amigos que se encontram para produzir o alimento e a cultura, numa síntese que constitui a sua própria cosmovisão de homem, de mundo e de relações. A Pedagogia da Alternância propõe interagir com esse movimento vital, garantindo a continuidade dessa dinâmica familiar e comunitária, favorecendo a otimização tempo-escola e tempo-comunidade no que concerne à construção de conhecimentos escolares significativos tanto para o aluno quanto para sua comunidade.

Não menos relevante e altamente circunstancial é a viabilidade de os alunos morarem na escola, durante o tempoescola, sem precisar aventurar-se em longos trajetos diários para retorno às suas casas, muitas vezes em condições precárias de transporte, mesmo quando ele é oferecido pelos órgãos públicos. Nesse momento, as relações sociais entre os que vivem aquele espaço se multiplicam, 
enraízam, criam novas referências, e a escola passa a se constituir, também, como comunidade.

Outrossim, a interrelação e a interdependência das populações do campo com o meio natural, seus fenômenos e ciclos indicam, essencialmente, que também o calendário escolar deve respeitar as premissas da Alternância, o que, por outro lado, aponta desafios. Um deles é o de uma escolarização que possibilite e contribua para que esse modo de vida secular e de traço étnico-cultural camponês não seja alterado por uma instituição que deve formar para a coesão sócio-cultural e não para sua desagregação. O calendário deve prever a Alternância temporal, mas, indo além, deve prever o tempo das comunidades na tradição do fazer educação, e no trabalho, com conhecimentos sobre o modo de produzir, de ter fé e de se divertir, enfim no trato dos conhecimentos tradicionais - e dos novos também, já que está no mundo e com o mundo. Nesse sentido, torna-se necessária a construção de um calendário escolar "colado" a um currículo - bojo conceitual político-pedagógico e didáticometodológico por onde caminha a escola adequado às diversas realidades das comunidades escolares do campo. E este é o desafio dado: a Alternância deve, também, estabelecer uma intensa relação entre comunidade, calendário e currículo.

\section{Simetrias entre os princípios epistemológicos da Alternância e os da Educação Popular}

O saber ocidental moderno se constituiu sobre fundamentos dicotômicos de mundo, potencializados pelo modo de produção capitalista, influenciando a produção do conhecimento em todas as áreas, com intensidade e valoração distintas. Quando os Semitas construíram a noção de sabedoria atrelada à arte de fazer uma coisa bem feita, e designaram o sábio como aquele que tem a posse do saber vinculado ao ensino e à instrução, estabeleceram a pedra angular que relaciona saber, poder e classe. Com a figura do "sábio" cria-se, por conseguinte, a figura do "não sábio", sendo que aquele assume a responsabilidade por "... ditar e conservar as normas sociais que orientam a prática do viver dos que não possuem aquele tipo de saber". (Oliveira, 2016, p. 27), constituindo uma iniciativa teórica direcionada ao campo da prática. Os Gregos herdaram essa sabedoria ressaltando como base do pensamento a filosofia, com o saber assumindo “... um caráter teorético, contemplativo e racional por se fundamentar na capacidade do ser humano de raciocinar e investigar os fatos 
de forma lógico-racional". (Oliveira, 2016, p. 27).

A Maiêutica Socrática e a Teoria Platônica das Ideias estabeleceram a concepção de teoria como o verdadeiro conhecimento, sublinhando no plano ontológico a existência de dois mundos, o inteligível - formado pelas ideias verdadeiras, perfeitas e eternas $-\mathrm{e}$ o mundo material sensível - das coisas materiais, cópias imperfeitas. " $\mathrm{O}$ verdadeiro conhecimento, então, é o conceitual, que se refere ao mundo das ideias e ao SER". (Oliveira, 2016, p. 30). Em tal perspectiva, há uma supremacia da atividade racional sobre a não racional. Instaura-se, portanto, a preponderância do teórico sobre o prático.

Em Aristóteles, encontra-se a formulação das bases do pensamento científico moderno, ao inverter a teoria platônica avançando para a ideia do conhecimento sensível - fatos, experiências - como origem do conhecimento racional e, portanto, ponto de partida para a construção da ciência (Oliveira, 2016). Para Aristóteles,

... a prática é um tipo de atividade que se caracteriza por sua imanência: seu desdobramento é o seu próprio fim; por ex.: o pensar, o querer, etc. Assim, a filosofia e toda sorte de atividade teórica são práxis no sentido mais próprio e nobre do termo. (Candau \& Lélis, 2005, p. $58)$.
No entanto, como o pensar estava restrito aos sábios, ao povo cabia o agir, a prática. Conforme Oliveira (2016, p. 41),

a teoria se apresenta entre os gregos como sistema explicativo dos fatos, uma atividade lógica, intelectual, exercício abstrato do raciocínio versus o concreto e o prático. ... Esse sentido metafísico de teoria, que reduz o conceito de teoria à abstração, analisa a prática de forma dicotomizada em relação à teoria.

Posteriormente, na Idade Média, os doutores escolásticos sublinharam a separação teoria e prática, traduzindo práxis por ação e póiesis por productio, dicotomizando os termos (Candau \& Lélis, 2005). Como, historicamente, a formação sistematizada foi legada a uma parcela social e economicamente privilegiada da sociedade, a escola transformou-se em reduto da teoria, do pensar, do elaborar, dado que essas eram as atribuições sociais de quem a frequentava. Às classes excluídas dessa benesse estava posta a tarefa de executar o pensado, estabelecendo-se a difícil reconciliação entre teoria e prática que, assenhorada pelo capitalismo, conserva a separação entre trabalho intelectual e trabalho manual, determinando a origem e a circulação do poder na sociedade, isto é, a divisão social do trabalho e dos bens produzidos por ele.

Desse modo, a separação, e às vezes oposição entre teoria e prática, quantidade 
e qualidade, sujeito e objeto, ter e ser segue determinando os papéis e os modos de produzir a vida, polarizando-os, muitas vezes, por meio de acepções de incompatibilidade entre um e outro. Não sem embargo, tentativas de conciliação entre tais paradigmas, sob a alegação de suas diversidades complementares acabam, também, por refutar-lhes suas essências. Santos Filho (2009), ao analisar esse posicionamento em obras diversas, conclui que há uma tendência de desepistemologização do debate ao se ignorar as diferenças paradigmáticas. Consequentemente, cai-se no pluralismo epistemológico considerado, ingenuamente, como apaziguador das oposições sustentadas pelos positivistas.

No decorrer da história, tanto as polarizações separatistas quanto as complementares serviram para diferenciar e classificar modos de conduta e de pensamento entre as classes conduzindo, muitas vezes, à dicotomização empedernida de tais termos, de modo que, em determinado momento, chega-se a promulgar sua impossível unidade.

A Pedagogia da Alternância não fica imune a tais polarizações quando se faz uma leitura das materialidades que se engendram na realidade, seja das Escolas Família-Agrícola, dos Centros Familiares de Formação por Alternância, seja de outras experiências que se produzem na Educação do Campo.

O relatório do Parecer 01/2006 (Brasil, 2006) sublinha tais equívocos epistemológicos que sustentam a perspectiva dicotômica que baliza muitas práticas que "adotam" essa Pedagogia. O relator Hingel (Brasil, 2006) a define como um método que “... ocorre por meio de períodos em que os alunos passam na família/comunidade duas semanas, alternando com outro período de uma semana (CFR) ou [de] duas semanas (EFA) no centro de formação, isto é, na escola". A visão dualista de tempo e espaço presente nessa concepção concorre para a separação teoria e prática nos âmbitos da escola e da comunidade, além de hierarquizar o tempo-espaço do pensar, em detrimento do tempo espaço do fazer, como fizeram os Semitas e os Gregos, e como o faz o sistema de capital. Ressaltase que “... na questão da relação teoria e prática, se manifestam os problemas e contradições da sociedade em que vivemos que, como sociedade capitalista, privilegia a separação trabalho intelectual-trabalho manual e, consequentemente, a separação entre teoria e prática". (Candau \& Lélis, 2005, p. 57).

Souza (2008) descreve que a falta de financiamento e organização políticopedagógica coloca em xeque a realização 
da Alternância, em uma EFA no Vale Jequitinhonha/MG. Silva (2017), ao investigar a Alternância em uma EFA norte-mineira, aponta a separação escola e comunidade em razão da ausência de intercâmbio formativo e participativo dos formadores comunitários no processo. Zancanella e Detogni (2019) sublinham as contradições que permeiam a experiência da Alternância no sudoeste do Paraná, envolvendo parcerias público-privadas; atendimento a alunos que residem em espaços urbanos (45\% da matrícula total); desatualização do regimento escolar, além da sua concepção escolanovista.

Como se pode depreender, na busca de conciliação entre escola e vida, por meio de uma das suas principais características, a relação tempo-escola e tempo-comunidade, as práticas que têm se proposto a desenvolver essa Pedagogia vêm construindo hibridismos epistemológicos, como ressalta Queiroz (2004), a partir de seus estudos: o justapositivo em que há separação entre períodos de trabalho e de estudo, sem nenhuma relação entre eles; o associativo com a junção aditiva da formação geral e formação profissional; e o integrativo real ou copulativo, quando se estabelece uma estreita conexão entre o tempo-escola e o tempo-comunidade sem primazia de um ou de outro. Neste caso, há uma ligação entre tais momentos, de forma integrada.

Os estudos de Zancanella e Detogni (2019, p. 17), citados anteriormente, sobre uma CFR no Paraná, sublinham uma experiência em que nem mesmo as formulações híbridas apresentadas por Queiroz (2004) se constituem: os 45\% dos alunos matriculados e que residem na zona urbana não vivenciam o tempocomunidade:

as circunstâncias de vida desses alunos ... impossibilita[m] que se articulem os tempos - espaços de formação. A A observação, confrontação, diálogos e constatações ficam comprometidos diante da não ruptura desses tempos e lugares. Sem ter como superar a fase do questionamento e da análise, esses alunos privam-se da prática, porque em algumas situações, no lugar de uma propriedade no campo, moram em uma casa na cidade, sem terra para dar continuidade ao que foi iniciado em suas observações e discutido na CFR. Diante disso, para muitos o que resta fazer é uma calçada com plantas cultivadas em vasilhames.

Realizar a Pedagogia da Alternância em qualquer uma das perspectivas híbridas - justapositiva, associativa, integrativa (Queiroz, 2004) ou dissociativa (Zancanella \& Detogni, 2019), é pensá-la centrada na separação teoria e prática, enquanto componentes de todo e qualquer processo de ensino e aprendizagem alternado e, portanto, dicotômico. Uma 
escola do campo, que encaminhe dessa forma a Pedagogia da Alternância, acaba por reforçar o modelo neoliberal de educação, que forma técnicos para o mercado de trabalho sem nenhum compromisso com o campo e com a emancipação dos povos campesinos.

\section{A unidade dos contrários como eixo fundante do papel político da epistemologia na Pedagogia da Alternância}

\section{O pensamento dicotômico encontra} seus parâmetros de existência no mundo da pseudoconcreticidade, “... um claro-escuro de verdade e engano". (Kosik, 2002, p. $15)$, que esconde o que não se quer que se veja, e revela o que se deseja conhecido. Ele desagrega ação e pensamento, naturalizando a ação social e manipulando a consciência. Nesse sentido, o mundo do pensar se restringe ao tempo-escola, e o da ação ao tempo-comunidade, como se esta estivesse sob a tutela intelectual da escola. Porquanto, a Alternância dualizada faz-se em dominação unificando a “... função intelectual, graças a qual se efetua a dominação dos sentidos, a resignação do pensamento em vista da produção da unanimidade, significa o empobrecimento do pensamento bem como da experiência: a separação dos dois domínios prejudica a ambos". (Adorno \& Horkheimer, 2006, p. 41). Por esse mecanismo, a práxis se torna um fetiche, alheia ao mundo real e às contradições que revelam a unidade do sim-não que forma a essência das coisas.

$\mathrm{Na}$ práxis fetichizada, em que se realiza a dicotomização teoria e prática, os fenômenos são apresentados independentes e imaginários, ocultando a verdadeira práxis. Por meio daquela práxis, escola e trabalho, ensinar e aprender, conhecimento informal e conhecimento científico, meio escolar e meio socioprofissional, escola e comunidade encontram-se ligadas, aproximadas, mas não em unidade, se auto-determinando e determinando uma a outra.

Pensar a Alternância em unidade alça a uma compreensão, pela qual se concebe tempo e espaço numa perspectiva indissociável, indissolúvel:

esta unidade é assegurada pela relação simultânea e recíproca de autonomia e dependência de uma em relação com a outra. $\mathrm{Na}$ verdade, essa simultaneidade e reciprocidade expressa o movimento das contradições nas quais os dois polos se contrapõem e se negam constituindo uma unidade. (Candau \& Lélis, 2005, p. 62).

Nessa perspectiva, a atividade, a reflexão sobre a atividade e os conhecimentos produzidos a partir da atividade comunicam-se visceralmente. Assim, compreende-se a atividade como “... ato ou conjunto de atos em virtude dos 
quais um sujeito (agente) modifica uma matéria-prima dada". (Vásquez, 2007, p. 220), o que contrapõe, diretamente, a ação à passividade. $\mathrm{E}$ essa atividade, enquanto humana, difere-se da atividade natural, dado que exige planejamento, projeção final, revelando a intencionalidade consciente da ação. Por conseguinte, se não há consciência nessa ação, ela se caracteriza pela alienação, ato desumanizado e mecânico. Por tal pressuposto, aliado à tese aristotélica de que pensar é uma ação, pode-se afirmar que o pensamento alienado não é consciente:

a atividade humana é, portanto, atividade que se orienta conforme a fins, e estes só existem através do homem, como produtos de sua consciência. Toda ação verdadeiramente humana exige certa consciência de um fim, o qual se sujeita ao curso da própria atividade. (Vásquez, 2007, p. 222).

O agir e o pensar, nessa acepção, encontram-se mediados pelos fins, o que, em momento algum, anula suas identidades e unifica as características próprias de cada ação. A Alternância, pensada como práxis, exige, então, a superação da ideia de escola como espaço do conhecimento teórico secular e a comunidade como espaço da prática, do fazer e do senso comum. A Alternância enquanto práxis é “... atividade teóricoprática; isto é, tem um lado ideal, teórico, e um lado material, propriamente prático, com a particularidade de que só artificialmente, por um processo de abstração, podemos separar, isolar um do outro". (Vásquez, 2007, p. 262). Não se trata, portanto, de articular teoria e prática, mas, sim, de compreender que teoria e prática existem em unidade, em reciprocidade. Esse princípio assenta-se na concepção de totalidade concreta, que concebe as múltiplas interdependências que se estabelecem no mundo real, quebra a pretensa independência dos fenômenos e das formas reificadas do mundo objetivo e real dado pela pseudoconcreticidade, revelando-os derivados e mediatos, “... como sedimentos e produtos da prática social da humanidade". (Kosik, 2002, p. 21). Nesse sentido, escola e comunidade são partes de uma realidade que supera a simples união dessas partes, constituindose no mundo dos meios, dos fins, dos instrumentos e dos esforços e exigências; é a unidade do fenômeno e da essência (Kosik, 2002). Nessa visão hologramática, a Alternância não representa interseções entre escola e comunidade por ser ela mesma o próprio significado e princípio da unidade.

Tempos e espaços, nesse sentido, não podem ser pensados separadamente, como se fossem independentes, mas sim pelas múltiplas interdependências que os 
constituem. Não se trata, portanto, de articulá-los ou possibilitar-lhes estar em interação. Trata-se de reconhecê-los como partes de uma totalidade que se encontra dialeticamente composta e agindo por contradições. Assim, "no Tempo Escola, projeta-se o Tempo Comunidade, e, neste último provoca-se o primeiro. Os tempos são contínuos no processo de aprendizagem, não se vive a escola sem pensar na comunidade e vice-versa". (Silva, 2017, p. 86). Escola e comunidade expressam-se como elementos da totalidade, da vida humana, que dialogam por aproximações e diferenças sem, contudo, quebrar a unidade. Escola e comunidade são tempos e espaços que formam alunos, professores, funcionários e famílias, sem interstícios, sem quebras, contraditoriamente. Assim, elas - escola e comunidade - expandem-se para além dos espaços físicos e geográficos que, muitas vezes, as limitam.

Nesse ponto, a tomada do contexto imediato onde se localizam escola e comunidade, e de onde vêm os alunos e suas famílias, é o ponto de referência para a produção da atividade de ensinar e de aprender que, envolvida pelo conhecimento científico, ascende a novas etapas de conhecimento, a outros espaços tanto próximos quanto distantes, e retorna ressignificada e, portanto, real e concreta.
Na perspectiva de Nascimento (2003, p. 1), além de se apresentar como “... resistência cultural em relação à forte hegemonia neoliberal presente na educação brasileira", a Alternância significa o processo de ensino e de aprendizagem que acontece em espaços e territórios diferenciados e alternados, mas que não se dissociam. Um é o espaço familiar e/ou a comunidade de origem, onde se forjam as vivências que singularizam o sentimento de pertença a um determinado grupo, a um povo, comungando saberes, culturas, modos de produzir a vida e perpetuar as gerações. O outro é a escola onde o educando partilha os diversos saberes que possui com outros sujeitos, e os certifica, relativiza-os, afirma-os ou os reconstrói tendo como referência as bases científicas. Local onde o encontro de saberes comunitários, singularizados no saber de cada sujeito, encontra o conhecimento científico, ressignifica-o permitindo-lhe ensinar e aprender. Há uma troca local e global de saberes e conhecimentos que vão retornar às famílias e comunidades, em forma de práxis, gerando outras formas de viver. Constitui-se, assim, uma rede de conhecimentos significativos que, seja na comunidade, na propriedade ou em determinados movimentos sociais, vão influenciar as condições de existência e de trabalho. Nesse movimento, tem-se claro 
que família, comunidade e escola são partes de um todo concreto e influenciado pelas multi-determinações resultantes do processo histórico. Esse todo concreto é sempre ponto de partida e de chegada tomando as ações ímpares como síntese de uma realidade, unidade do diverso. Constitui-se, assim, a produção de conhecimento em espiral, quando local e global, conhecimento popular e conhecimento científico se ressignificam e se retroalimentam em unidade.

Nesse processo formativo, revela-se o papel político da epistemologia presente na Pedagogia da Alternância. O ensino e a aprendizagem rompem com a visão utilitarista e fragmentada da realidade, colocam o aluno como ser que age e pensa, a partir da sua experiência, sobre a vida cotidiana local e global, capacitando-o para escolher, decidir, participar e transformar a si mesmo e os espaços onde vive. Desenvolve-se o pensamento crítico emancipador, isto é, dialético, que dissolve os fetiches pela compreensão da unidade entre os contrários. Quebra-se a dicotomia trabalho intelectual e trabalho manual rompendo com a práxis fragmentária, favorecendo a emergência de uma atmosfera espiritual em que a aparência superficial da realidade é fixada como natural, e não como produção humana.
Destarte, a epistemologia é o cerne emancipador da Pedagogia da Alternância e, ao negá-la, práticas justapostas, associativas, integrativas e dissociativas de alternância contrapõem-se ao seu papel político de “... elaborar ações que promovam o rompimento de uma visão de mundo fragmentada e acrítica dos oprimidos, objetivando a construção de uma nova realidade em que esses sujeitos possam intervir". (Freitas \& Freitas, 2018, p. 368).

O homem é o único ser capaz de transcender, isto é, de refletir sobre si, o outro e o mundo na busca pela compreensão da sua existência (Freire, 1967). Nessa busca, o saber experiencial, cultural, vivenciado no cotidiano, e o científico, intelectual, em interconexão, devem propiciar a ação-reflexão-crítica da realidade levando à transformaçãoemancipação do sujeito e da sociedade, constituindo-se em práxis. A produção de conhecimento algum admite o vazio. Daí que a alternância do ensino e da aprendizagem na escola, na família, na comunidade, nos movimentos pode gerar a emancipação. Tempo-escola e tempocomunidade não podem encontrar-se refratários um ao outro; não podem constituir-se em tempoescola/conhecimento científico e tempocomunidade/senso comum, dado que em 
todo conhecimento há faces de uma e de outra esfera. Portanto, além de ser constituído a partir do contexto do aluno e de sua comunidade, é a este mesmo contexto que o conhecimento deve retornar para transformar-emancipar.

A Alternância aparelha-se, portanto, como uma Pedagogia que, pelas suas possibilidades, referências, matizes e interfaces, em essência, atende aos preceitos da Educação Popular e, por consequência, da Educação do Campo. Para Gimonet (2007, p. 42), essa Pedagogia supõe "... passagens e transições de um lugar de vida a outro, de um tipo de experiência a outro".

É preciso dizer que compreender a Alternância como unidade orienta não apenas o currículo e a organização escolar, mas também as relações que se estabelecem entre família, escola, alunos, monitores, professores, funcionários $\mathrm{e}$ direção abarcando os conflitos e as contradições que se colocam no interior e no exterior do espaço escolar e da própria comunidade. Nesse âmbito, o diálogo se põe como alternativa de enfrentamento e crescimento que não estaciona os posicionamentos no que já está posto, dado, mas, sim, impele-os a avançarem nas proposições, ideias e ações tendo como referência a melhoria da vida e do trabalho dos sujeitos envolvidos nesse processo.
Compreender a unidade como princípio da Alternância coloca a formação dos envolvidos, e não apenas a dos alunos, sob a perspectiva da formação omnilateral, em totalidade, tomando a perspectiva do trabalho como catalizador, elemento emancipador e, portanto, elemento central. Aprender teorias aplicáveis ou replicáveis às práticas, dentro e fora da escola, não abarca a Alternância. Se a vida cotidiana, na sua totalidade, não é, por si só, o ponto de eclosão das possibilidades de ensino e de aprendizagem, tendo as propostas curriculares como orientadoras, instaura-se um modo de escolarização pseudoconcreto. Da mesma forma que as propostas curriculares não são referências únicas ou vitais da formação, sem elas cai-se no espontaneísmo, que rouba do aluno o acesso ao conhecimento científico em unidade com seu conhecimento produzido antes e durante a imersão na escola.

Por essência, a Alternância é elemento de emancipação dos envolvidos (alunos, profissionais da escola, famílias, comunidades) para si, em si e para além de si, enquanto sujeitos e classe. Ela prepara para a emancipação enquanto eixo da vida e do trabalho, pois as relações cotidianas não se circunscrevem ou se encerram no âmbito da escola ou da comunidade. Elas se estendem à própria vida, em tempos e espaços diversos. 
A Pedagogia da Alternância que se fecha no binômio escola-comunidade não avança na formação para além do imediato, não forma os sujeitos para enfrentarem as relações sócio-políticas-culturaiseconômicas que estão para além da profissão, e se interpõem diretamente sobre a vida. A Alternância coloca as contradições

sujeito/sociedade/trabalho/emprego/formaç ão/sustentabilidade/conformação/emancipa ção em constante debate sem refutar seus desdobramentos sobre a vida em e para a comunidade. Assim,

... não é suficiente a aproximação ou a ligação de dois lugares com suas lógicas diferentes e contraditórias, ou seja, a escola e o trabalho. É necessária uma sinergia, uma integração, uma interpenetração rompendo com a dicotomia teoria e prática, abstrato e concreto, saberes formalizados e habilidades (saberfazer), formação e produção, trabalho intelectual e trabalho físico (manual). (Queiroz, 2004, p. 27-28).

Somente assim pode-se constituir uma Pedagogia que contemple a unidade das epistemologias da Educação Popular: a dialogicidade, que torna possível a horizontalidade das relações comprometidas com a supressão da opressão tendo a realidade concreta como ponto de partida e de chegada; a conscientização que possibilita a produção de massa crítica, enquanto compromisso histórico com as classes populares, e que pode transformar a realidade pela práxis revolucionária. Somente assim a Alternância dialoga com os preceitos da Educação Popular e pode se constituir em elemento de emancipação dos povos do campo.

\section{Considerações finais}

O acúmulo de reflexões sobre a alternância dos tempos e espaços de ensino e de aprendizagem tem conseguido avançar como uma concepção que coloca diversos aspectos políticos, pedagógicos e epistemológicos em pauta. É o próprio direito à diversidade, a um atendimento escolar contextualizado para populações diferenciadas que está em xeque. Hoje, quando o debate nacional se volta para a diversidade étnico-cultural e seus direitos, cabe às instâncias e sistemas educacionais considerarem que à escola também está colocado o desafio de apresentar alternativas viáveis para a mudança no quadro de desigualdade e exclusão social causado grandemente pela negligência escolar a que essas populações estão sujeitas; exclusão de milhões de cidadãos, de grupos étnicos diferentes, que remete à desconsideração da riqueza do patrimônio cultural do nosso país.

Nesse cenário, práticas híbridas, que desconsideram o princípio epistemológico- 
político da Pedagogia da Alternância, pouco colaboram para a emancipação dos povos do campo, terminando por se estabelecer a alternância apenas como mais uma "novidade" metodológica. Transcender tal perspectiva requer estudo, diálogo e compromisso com os princípios formativos e emancipatórios da Educação Popular e de Uma Educação Do Campo.

Sem dúvida, a efetivação da Pedagogia da Alternância como alternativa pedagógico-formativa emancipadora é um grande desafio porque se opõe à lógica educacional que impregna os atos educacionais ladeados pelos princípios neoliberais do atual sistema do capital. A Alternância se opõe à lógica dual excludente que organiza a sociedade brasileira, e que separa e hierarquiza teoria e prática; classes sociais; trabalhadores e donos dos modos de produção; quantidade e qualidade; ter e ser.

Vencer a dualidade presente na compreensão do tempo-escola e do tempocomunidade, numa perspectiva de Alternância, é uma necessidade premente aos processos de luta das populações do campo para sua inserção na dinâmica da troca de bens culturais e no fortalecimento da identidade étnico-cultural brasileira; para a realização material dos direitos já reconhecidos por lei; para a emancipação dos povos do campo; para uma Educação

Do Campo; por uma Educação Popular.

\section{Referências}

Adorno, T. W., \& Horkheimer, M. (2006). Dialética do esclarecimento. Fragmentos filosóficos. Rio de Janeiro, RJ: Jorge Zahar.

Brasil. (1988). Constituição da República Federativa do Brasil. Brasília.

Brasil. (1996). Lei n. 9.394, de 20 de dezembro de 1996. Estabelece as Diretrizes e Bases da Educação Nacional. Brasília.

Brasil. (2002). Resolução CNE/CEB $n^{\circ} 1$ de 3 de abril de 2002. Institui Diretrizes Operacionais para a Educação Básica nas Escolas do Campo. Brasília.

Brasil. (2006). Parecer $n^{o} 1$ de 15 de março/2006. Trata dos dias letivos para a aplicação da Pedagogia de Alternância nos Centros Familiares de Formação por Alternância (CEFFA). Brasília.

Brasil. (2008). Resolução $n^{o} 2$, de 28 de abril de 2008. Estabelece Diretrizes Complementares, Normas e Princípios para o Desenvolvimento de Políticas Públicas de Atendimento da Educação Básica do Campo. Brasília.

Brasil. (2018). Plano Nacional de Educação 2014-2024. Brasília.

Calazans, M. J. C., Castro, L. F. M., \& Silva, H. R. S. (1981). Questões e Contradições da Educação Rural no Brasil. In Werthein, J., \& Bordenave, J. D. (Orgs.). Educação Rural no Terceiro Mundo - experiências e novas alternativas (pp. 161-198). Rio de Janeiro, RJ: Paz e Terra. 
Caldart, R. (2012). Educação do Campo. In Caldart, R. et al. (Orgs.). Dicionário da Educação do Campo (pp. 257-265). Escola Politécnica de Saúde Joaquim Venâncio/Expressão Popular. Rio de Janeiro.

Caldart, R. (2011). Por uma educação do campo: traços de uma identidade em construção. In Arroyo, M. G., Caldart, R. S., \& Molina, M. C. (Orgs.). Por uma educação do campo (pp. 149-158). Rio de Janeiro, RJ: Vozes.

Candau, V. M., \& Lélis, I. A. (2005). A relação teoria-prática na formação do educador. In Candau, V. M. (Org.). Rumo a uma nova didática (pp. 56-72). Petrópolis, RJ: Vozes.

Cruz, P., \& Monteiro, L. (2019). $O$ Anuário Brasileiro da Educação Básica/2019. Recuperado de: https://www.todospelaeducacao.org.br/_up loads/_posts/302.pdf

Freire, P. (1967). Educação como prática de Liberdade. Rio de Janeiro, RJ: Paz e Terra.

Freitas A. L. C., \& Freitas, L. A. A. (2018). A construção do conhecimento a partir da realidade do educando. Revista On line de Política e Gestão Educacional, 22(1), 365-380, Doi: https://doi.org/10.22633/rpge.v22.n.1.2018 .10707

Gimonet, J. C. (2007). Praticar $e$ Compreender a Pedagogia da Alternância dos CEFFAS. Rio de Janeiro, RJ: Vozes.
Guia do Estudante. (2010). Pesquisa avalia escolas rurais brasileiras e detecta problemas de infraestrutura. Recuperado de:

https://guiadoestudante.abril.com.br/estudo /pesquisa-avalia-escolas-rurais-brasileirase-detecta-problemas-de-infraestrutura/

Kosik, K. (2002). Dialética do concreto. Rio de Janeiro, RJ: Paz e Terra.

Movimento de Educação de Base. (2019). Quem somos. Recuperado de: https://www.meb.org.br/quem-somos/

Nascimento, C. G. (2003). Pedagogia da resistência cultural: um pensar a educação a partir da realidade campesina. In VIII Encontro Regional de Geografia (EREGEO). Cidade de Goiás, GO.

Oliveira, I. A. (2016). Epistemologia e Educação - bases conceituais $e$ racionalidades científicas e históricas. Petrópolis, RJ: Vozes.

Queiroz, J. B. (2004). Construção das escolas famílias agrícolas no Brasil: ensino médio e educação profissional (Tese de Doutorado). Universidade de Brasília, Brasília.

Reis, T., \& Moreno, A. C. (2015). Brasil urbano X Brasil rural. Recuperado de http://especiais.g1.globo.com/educacao/20 15/censo-escolar-2014/brasil-urbano-Xbrasil-rural.html

Santos Filho, J. C. (2009). Pesquisa quantitativa versus pesquisa qualitativa: o desafio paradigmático. In Santos Filho, C., \& Gamboa, S. S. (Orgs.) Pesquisa educacional: quantidade-qualidade (pp. 10-32). São Paulo, SP: Cortez.

Silva, L. L. (2017). Dois tempos, vários lugares: trabalho e emancipação em alternância (Tese de Doutorado). 
Universidade Federal de Minas Gerais, Minas Gerais.

Silva, L. L., \& Martins, M. F. A. (2015). Outra perspectiva para a Educação do Campo. Caderno de Ciências Agrárias, 7(1), 89-101.

Souza, J. V. A. (2008). Pedagogia da alternância: uma alternativa consistente de escolarização rural? In Anais da $31 a$ Reunião da ANPED. Recuperado de http://www.anped.org.br/reunioes/31ra/1tra balho/GT14-4500--Int.pdf

Vázquez, A. S. (2007). Filosofia da práxis. Buenos Aires, AR: Consejo Latinoamericano de Ciencias Sociales CLASCO; São Paulo, SP: Expressão Popular.

Zancanella,Y., \& Detogni, A. A. (2019). Pedagogia da Alternância proposta de formação: Casa Familiar do município de Coronel Vivida-PR. Revista Brasileira de Educação do Campo, 4(1), 1-28. Doi: http://dx.doi.org/10.20873/uft.rbec.v4e493 $\underline{6}$

\section{Informações do artigo / Article Information}

Recebido em : 31/07/2019

Aprovado em: 30/09/2019

Publicado em: 19/12/2019

Received on July 06th, 2019

Accepted on September 25th, 2019

Published on December, 19th, 2019

Contribuições no artigo: Os autores foram responsáveis por todas as etapas e resultados da pesquisa, a saber: elaboração, análise e interpretação dos dados; escrita e revisão do conteúdo do manuscrito e; aprovação da versão final publicada.

Author Contributions: The author were responsible for the designing, delineating, analyzing and interpreting the data, production of the manuscript, critical revision of the content and approval of the final version published.

Conflitos de interesse: Os autores declararam não haver nenhum conflito de interesse referente a este artigo.

Conflict of Interest: None reported.

\section{Orcid}

Úrsula Adelaide de Lélis

iD http://orcid.org/0000-0002-4683-4444

Magda Martins Macedo

iD http://orcid.org/0000-0001-5980-516X

Leandro Luciano da Silva

iD http://orcid.org/0000-0002-8903-6442

Maria Auxiliadora Amaral Silveira Gomes

(iD) http://orcid.org/0000-0002-2028-0420

Como citar este artigo / How to cite this article

APA

Lélis, U. A., Macedo, M. M., Silva, L. L., \& Gomes, M. A. A. S. (2019). Pedagogia da Alternância e Educação do Campo: dos hibridismos epistemológicos à simetria com a Educação Popular. Rev. Bras. Educ. Camp., 4, e7323. DOI: http://dx.doi.org/10.20873/uft.rbec.e7323

ABNT

LÉLIS, U. A.; MACEDO, M. M.; SILVA, L. L.; GOMES, M. A. A. S. Pedagogia da Alternância e Educação do Campo: dos hibridismos epistemológicos à simetria com a Educação Popular. Rev. Bras. Educ. Camp. Tocantinópolis, v. 4, e7323, 2019. DOI: http://dx.doi.org/10.20873/uft.rbec.e7323 